\title{
Chemotherapy-induced peripheral neuropathy (CIPN): current therapies and topical treatment option with high-concentration capsaicin
}

\author{
Christian Maihöfner ${ }^{1}$ (D) Ingo Diel ${ }^{2} \cdot$ Hans $^{T^{2}}$ Iech $^{3} \cdot$ Tamara Quandel $^{4} \cdot$ Ralf Baron $^{5}$
}

Received: 3 November 2020 / Accepted: 3 February 2021 / Published online: 23 February 2021

(C) The Author(s) 2021

\begin{abstract}
Cancer diagnosis and treatment are drastic events for patients and their families. Besides psychological aspects of the disease, patients are often affected by severe side effects related to the cancer itself or as a result of therapeutic interventions. Particularly, chemotherapy-induced peripheral neuropathy (CIPN) is the most prevalent neurological complication of oral or intravenous chemotherapy. The disorder may require dose reduction of chemotherapy and is accompanied by multiple symptoms with longterm functional impairment affecting quality of life (QoL), e.g., sensory and functional deteriorations as well as severe pain. Although CIPN may reverse or improve after termination of the causative chemotherapy, approximately 30-40\% of patients are faced with chronicity of the symptoms. Due to the advantages in cancer diagnosis and treatments, survival rates of cancer patients rise and CIPN may occur even more frequently in the future. In this review, we summarize current recommendations of leading national and international societies regarding prevention and treatment options in CIPN. A special focus will be placed on current evidence for topical treatment of CIPN with high-dose capsaicin. Finally, an algorithm for CIPN treatment in clinical practice is provided, including both pharmacologic and non-pharmacologic modalities based on the clinical presentation.
\end{abstract}

Keywords Chemotherapy-induced peripheral neuropathy $\cdot$ Cancer $\cdot$ Neuropathic Pain $\cdot$ Capsaicin

\section{Introduction/background}

According to the International Association of the Study of Pain (IASP) neuropathic pain is defined as pain caused by a lesion or disease of the somatosensory (peripheral and/or central) nervous system and comprises a loss of sensory function or sense as well as an increased pain sensitivity or spontaneous pain $[1,2]$. Cancer-related neuropathic pain may result from

Christian Maihöfner

neurologie@klinikum-fuerth.de

1 Department of Neurology, Fürth General Hospital, Jakob-Henle-Straße 1, 90766 Fürth, Germany

2 Praxisklinik Am Rosengarten, Mannheim, Germany

3 Department of Oncology, Bethanien Hospital, Frankfurt am Main, Germany

4 Grünenthal GmbH, 52078 Aachen, Germany

5 Division of Neurological Pain Research and Therapy, Department of Neurology, University Hospital of Schleswig-Holstein, Campus Kiel, Kiel, Germany direct infiltration of the primary tumor or metastases or from cancer treatments, including surgery, radiotherapy, and chemotherapy [3]. Particularly, chemotherapy-induced peripheral neuropathy (CIPN) represents a common and disabling side effect of tumor treatment with neurotoxic antitumor agents causing damage to peripheral nerves (sensory, motor, and autonomic). Although neurotoxicity levels of these substances vary, some are known to be associated with an increased risk of CIPN, e.g., platinum derivatives, taxanes, vinca alkaloids, eribulin, bortezomib, and thalidomide [4-6].

Symptoms of CIPN usually decline after termination of the neurotoxic therapy. However, depending on the administered substance (e.g., platinum compounds), further progression or new development of symptoms for several months posttherapy is possible (coasting phenomenon), and symptoms can persist for many years or even lifelong [7]. Since certain chemotherapeutic agents (e.g., cisplatin) remain in the body for a long time [8], CIPN symptoms can also develop and manifest years after completion of chemotherapy. Thus, even chemotherapies from long ago should be considered at diagnosis of emerging neuropathies, especially in conjunction with further 
predispositions (e.g., genetic, environmental, and life-style factors such as alcohol abuse). Some neurotoxic chemotherapeutic agents cause both acute and chronic forms of neuropathy. As an example, the frequent acute form of oxaliplatin-induced peripheral neuropathy (mainly cold-induced distal paresthesia, dysesthesia, or pain) normally reverses within a week. The chronic cumulative form persists between and after treatment. While in most patients, the severe chronic form resolves within approximately 13 weeks after treatment, a considerable number of patients still experience chronic neuropathic symptoms after more than a year [9]. The severity of chronic neuropathy seems to correlate with that of acute symptoms, and an early development of cold hyperalgesia has been suggested as predictor of severe chronic oxaliplatin-induced CIPN [10].

Approximately $50-90 \%$ of patients under chemotherapy are affected by CIPN and bear a high risk of chronicity (approx. 3040\%) [11-13]. A recent meta-analysis published by Rivera et al. revealed that CIPN-associated neuropathic symptoms persist in 11 to $>80 \%$ of early-stage breast cancer patients for $1-3$ years following therapy. Particularly in light of the excellent survival prognosis of this patient cohort, it is essential to consider CIPNrelated impairments in quality of life (QoL) [14].

Sensory nerve fibers are generally more vulnerable to toxic effects of anticancer drugs and patients affected by CIPN usually experience greater sensory than motor or autonomic symptoms. CIPN-specific symptoms commonly manifest in feet and hands in typical sock and/or glove-like pattern. They may cause adjustments of therapy as well as subsequent reduction in treatment efficacy [11].

The pathophysiology of CIPN upon administration of anticancer therapies has been analyzed in detail by a variety of studies and reviews $[11,12,15,16]$. Although the exact pathogenesis is still not fully understood, the underlying mechanism of CIPN is regarded to be multifactorial with various sites of involvement. Chemotherapeutic drugs exert neurotoxic effects on myelin sheets (myelinopathy), on sensory cell bodies in the dorsal root ganglion (neuronopathy), and on axonal components (axonopathy), including ion channels, microtubules, mitochondria, and associated capillaries (Fig. 1). Subsequently, common degenerative pathways are triggered leading to the production of pro-inflammatory cytokines, activation of apoptotic signaling cascades, and alteration of neuronal excitability which might consequently result in epidermal fiber loss [18, 19]. In addition to peripheral neuronal dysfunction, long-term changes in the central nervous system may result in chronic pain [15].

\section{Clinical presentation and diagnostics}

\section{Prevalence and risk factors}

In general, prevalence and incidence of CIPN vary according to the chemotherapeutic agent, dose, duration of exposure, and method of assessment [17]. According to metadata (31 studies with a total of 4179 patients), CIPN prevalence amounts up to $68 \%$ within the first month after chemotherapy, $60 \%$ after 3 months, and $30 \%$ after 6 months [20]. Importantly, CIPN-related symptoms often persist $>6$ months after cessation of chemotherapy, and there is evidence for a relationship between QoL and the severity of neuropathy [14, 21]. Further data evaluating the long-term consequences of docetaxel treatment in breast cancer and oxaliplatin treatment in colorectal cancer patients revealed that $42 \%$ and $84 \%$ of patients, respectively, displayed CIPN symptoms 2 years after therapy $[22,23]$. In addition, a systemic review found persistent CIPN-related symptoms in $11 \%$ to more than $80 \%$ of the studied breast cancer patients at 1 to 3 years after chemotherapy [14]. Thus, although overall severity of peripheral neuropathy declines and sensory nerve conduction improves over time, recovery is often incomplete.

Besides specific risk factors such as diabetes, hypothyroidism, renal insufficiency, alcohol abuse, and preexisting neuropathy (e.g., diabetic neuropathy), there are tumor-associated and therapy-related factors that contribute to the individual risk for CIPN [6]. However, nature and severity of CIPN mainly correlate with the administered neurotoxic agent, the administered cumulative dose, and the duration of exposure (Table 1).

\section{Evaluation of CIPN-specific symptoms and disease- related burden}

CIPN is predominantly a sensory neuropathy that may be accompanied by motor and autonomic deficits, depending on the chemotherapy regimen (Table 1, Fig. 2). Sensory dysfunctions can generate positive symptoms as well as negative symptoms.

Positive sensory symptoms can be stimulus-evoked or spontaneous and include:

- hyperalgesia (increased response to a normally painful stimulus)

- allodynia (increased response to a normally non-painful stimulus), resulting from thermal and mechanical (dynamic, static, and vibration) stimuli

- spontaneous (i.e., stimulus-independent, ongoing, or paroxysmal) shooting pain, electric shocks, or burning pain

- dysesthesia (abnormal, unpleasant, and/or painful sensation felt in the skin)

- paresthesia (abnormal sensation that is distracting but not generally painful)

Negative sensory symptoms include:

- reduced responses to either normally non-painful or painful stimuli in the damaged nerve territory (i.e., hypoesthesia or hypoalgesia) causing a feeling of numbness 
Fig. 1 Putative targets of toxicity of chemotherapeutic agents. Neurotoxicity of different chemotherapeutic agents is mediated by interference with a variety of cellular structures and components of the peripheral nervous system, modified from $[16,17]$

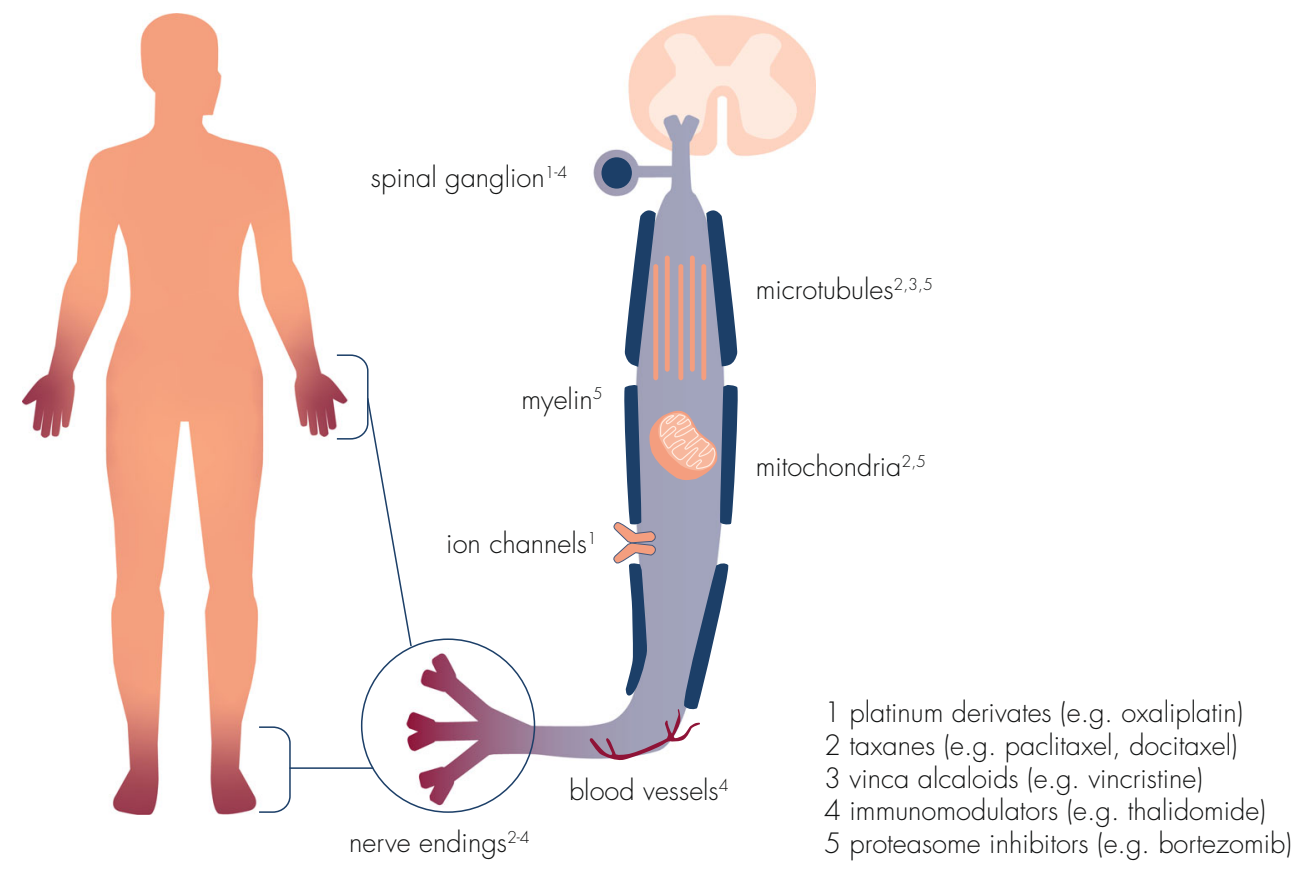

- impaired fine motor skills (e.g., difficulties in closing buttons or holding a pen)

- disturbance of vibratory and proprioceptive sensations

The longest peripheral axons are more vulnerable to toxic drugs, and sensory symptoms usually begin in the lower limbs followed by the upper extremities, spreading from toes and fingertips in a distal symmetric sock- and glove-like distribution pattern. Most patients (approx. 68\%) are simultaneously affected at upper and lower limbs, although presence of symptoms exclusively in the feet is also possible [24]. Additionally, malfunctions of the motor nervous system, e.g., paresis, cramps of the muscles, or attenuated reflexes, can occur. Motor neuropathy is more frequently seen with paclitaxel and vincristine and may manifest as weakness in arms and legs with difficulties in opening a bottle, walking stairs, or standing. In some cases, most commonly with exposure to vinca alkaloids, the autonomic nervous system is included, with symptoms like orthostatic hypotension, cardiovascular or urogenital dysfunction, and gastroparesis [17]. Since most patients receive multiple potentially neurotoxic agents, additive or synergistic effects are possible.

CIPN-associated QoL deteriorations including increased risk of falling are burdensome for patients and often underestimated by physicians $[4,25,26]$. Similarly, reports by patients and clinicians lead to highly different CIPN severity scores, and patient-reported outcomes typically reveal greater neurotoxicity than clinician assessment [27, 28]. Consequently, there is a need for assessment of both patients' and clinicians' perspectives to adequately rate and treat CIPN symptoms [28]. In addition, comparing CIPN symptom assessment via patient-reported outcomes and quantitative sensory testing (QST), which measures the detection threshold of sensory stimuli to quantify changes in nociceptive, thermal, and vibration perception, displayed weak-to-moderate correlations in breast cancer patients. However, with respect to pain, numbness, tingling, and reduction in tactile and vibration perception, QST outcomes appear to be more closely associated with CIPN symptoms, and thus might be considered for monitoring and support of CIPN therapy [29].

\section{Diagnostics}

Guidelines by national and international societies recommend neurological examination of cancer patients prior to initiation of potentially neurotoxic cancer therapies in order to obtain a neurological baseline status and identify patients at risk of CIPN [6, 7]. Important clinical conditions that may predispose patients for CIPN include preexisting peripheral nervous system dysfunctions such as radiculopathy, diabetic neuropathy, or Charcot-Marie-Tooth disease [16].

Once CIPN is presumed, further diagnosis is made by history and clinical presentation [5, 6]. Bedside testing for assessment of negative and positive sensory symptoms can be useful to find possible abnormalities suggestive of a relevant lesion or disease which affects the somatosensory system [30]. Decreased or increased tactile senses are best assessed with a cotton swab or wooden stick, thermal sense with warm and cold objects, and vibration sense with a tuning fork (supplemental table 1). Diagnosis can be supported by patients' documentation of neurotoxic complaints and assessment of QoL, e.g., by using the European Organization for Research and Treatment of Cancer (EORTC), QoL Questionnaire-CIPN-twenty-item scale (QLQ-CIPN 20), or 
Table 1 Specific toxicity profiles of neurotoxic chemotherapeutic agents, modified from $[6,17]$

\begin{tabular}{|c|c|c|c|c|c|}
\hline \multicolumn{2}{|l|}{ Cancer therapy } & \multirow{2}{*}{$\begin{array}{l}\text { Increased risk of } \\
\text { neurotoxicity }\end{array}$} & \multicolumn{2}{|l|}{ Incidence } & \multirow[t]{2}{*}{ Symptoms } \\
\hline Substance & Class & & $\begin{array}{l}\text { Grade } 1- \\
2^{*}\end{array}$ & $\begin{array}{l}\text { Grade } \\
3-4^{*}\end{array}$ & \\
\hline Cisplatin $^{1,2}$ & Platinum & $>300-350 \mathrm{mg} / \mathrm{m}^{2}$ & $14-63 \%$ & $7-21 \%$ & $\begin{array}{l}\text { - Predominantly sensory neuropathy } \\
\text { - Painful paresthesia, numbness, tingling, impaired } \\
\text { vibration sense, sensory ataxia }\end{array}$ \\
\hline Oxaliplatin ${ }^{1,2,4,6}$ & Platinum & $>550 \mathrm{mg} / \mathrm{m}^{2}$ & $18-100 \%$ & $12-39 \%$ & $\begin{array}{l}\text { - Acute sensory symptoms and chronic sensory } \\
\text { neuropathy } \\
\text { - Acute cold-induced paresthesia, cramps, fascicu- } \\
\text { lations }\end{array}$ \\
\hline $\begin{array}{l}\text { Paclitaxel } \\
\text { Docetaxel }^{1,2,4}\end{array}$ & Taxane & $\begin{array}{l}>250-300 \mathrm{mg} / \mathrm{m}^{2} \\
>100 \mathrm{mg} / \mathrm{m}^{2}\end{array}$ & $20-50 \%$ & $6-20 \%$ & $\begin{array}{l}\text { - Predominantly sensory neuropathy } \\
\text { - Painful paresthesia, numbness } \\
\text { - Decreased vibration or proprioception } \\
\text { - At higher doses, myalgia and myopathy }\end{array}$ \\
\hline Vincristine $^{1,2}$ & Vinca alkaloid & $>2-6 \mathrm{mg} / \mathrm{m}^{2}$ & $35-45 \%$ & & $\begin{array}{l}\text { - Sensory neuropathy } \\
\text { - Hypoesthesia (up to } 100 \% \text { ), tingling paresthesia } \\
\text { - Muscle cramps and mild distal weakness } \\
\text { - Autonomic neuropathy }\end{array}$ \\
\hline Thalidomide ${ }^{1,5}$ & $\begin{array}{l}\text { Immunomodulatory/antiangiogenic } \\
\text { agent }\end{array}$ & $>20 \mathrm{~g}$ & $\leq 83 \%$ & $\leq 35 \%$ & $\begin{array}{l}\text { - Sensory neuropathy } \\
\text { - Muscle cramps and mild distal weakness }\end{array}$ \\
\hline Bortezomib $^{1,2,3}$ & Proteasome inhibitor & $>16-26 \mathrm{mg} / \mathrm{m}^{2}$ & $\leq 50 \%$ & $\leq 30 \%$ & $\begin{array}{l}\text { - Painful, small-fiber sensory neuropathy } \\
\text { - Painful paresthesia, burning sensation, sensory } \\
\text { ataxia } \\
\text { - Autonomic neuropathy including orthostatic } \\
\text { hypotension }\end{array}$ \\
\hline Eribulin & Microtubule inhibitor & n.a. & n.a. & n.a. & $\begin{array}{l}\text { - Sensory neuropathy } \\
\text { - Myalgia } \\
\text { - Note: almost all patients are pretreated with } \\
\quad \text { (multiple) neurotoxic cancer therapies }\end{array}$ \\
\hline
\end{tabular}

\footnotetext{
${ }^{1}$ Increased single doses are associated with greater neurotoxicity

${ }^{2}$ Increased cumulative doses are associated with greater neurotoxicity

${ }^{3}$ Dose threshold relationship, increasing risk until a plateau at 40 to $45 \mathrm{mg} / \mathrm{m}^{2}$

${ }^{4}$ Longer infusion duration may reduce neurotoxicity

${ }^{5}$ Longer duration of treatment increases the risk of neurotoxicity

6 "Stop-and-go" regimens may be associated with lower neurotoxicity

*NCI-CTCAE scale
}

clinician-assessed neuropathy scores (e.g., Total Neuropathy Score, TNS). The QLQ-CIPN20 is a 20-item questionnaire evaluating sensory, motor, and autonomic symptoms and function with each item measured on an ordinal 1-4 scale (1, not at all; 4, very much) [31]. The complete version of the TNS has been used as a reliable tool for accessing the presence and severity of CIPN [32]. In addition, modified versions have been developed, known as TNS-reduced (TNSr) scale and TNS-clinical (TNSc) scale which have been validated in a multicenter setting in patients with CIPN [33]. Diagnosis may also be supported by application of specific tools for neuropathic pain screening such as painDETECT®, which contains nine sensory symptom items and was designed for detection and documentation of pain in practice and clinic [34]. Likewise, DN4 (Neuropathic Pain in 4 Questions), another useful screening tool to estimate the probability of neuropathic pain, contains questions to the patient as well as items based on clinical examination [35]. In addition, nerve conduction studies (NCS), electromyography (EMG), and QST can support clinical assessment of CIPN [5]. Although not routine, skin biopsies might be carried out to support diagnosis, especially in patients with neuropathic pain in whom other diagnostic tools are normal or negative, e.g., in CIPN resulting from small nerve fiber dysfunction. The method can be included in the diagnostic assessment as well as for followup of patients with peripheral neuropathy [36].

As some chemotherapeutic substances can provoke polyneuropathy-like symptoms, differential diagnoses, e.g., palmoplantar erythrodysesthesia (also called as "hand-foot syndrome") after treatment with capecitabine or pegylated doxorubicin or paraneoplastic neuropathy mediated by onconeural antibodies targeting peripheral 


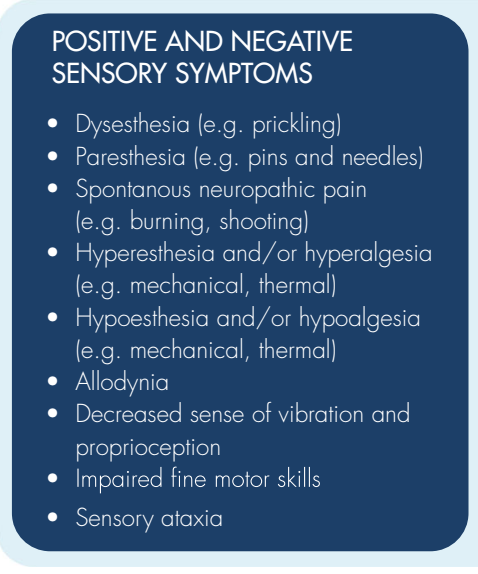

Fig. 2 Clinical features of CIPN depending on the type of affected peripheral nerves (sensory, motor, or autonomic). CIPN is predominantly a distal symmetrical sensory neuropathy with sensory abnormalities in lower arms and lower legs (stocking/glove

nervous system epitopes, should be considered to ensure appropriate treatment $[6,17]$. Furthermore, other rare neuropathies like erythromelalgia may also cause symptoms similar to CIPN [37].

\section{Therapy of CIPN}

\section{Prophylactic interventions to prevent CIPN-associated functional loss}

Several compounds have been investigated in clinical studies for their efficiency in prevention of CIPN, including anticonvulsants, antidepressants, vitamins, minerals, and other chemoprotectants without reliable or conclusive clinically meaningful benefits $[6,7,38]$. Hence, there is no strong evidence for an established or recommended medical prophylaxis of CIPN. However, dose adjustment algorithms may contribute to the reduction of higher grade CIPN while maintaining treatment efficacy in individual patients [6]. Furthermore, literature data suggest extremity cooling during administration of certain chemotherapeutic agents (e.g., taxanes) as an option for reduction of severity, when CIPN development or symptom worsening can be expected $[39,40]$.

Upon initiation of potential neurotoxic anticancer therapies, regular functional exercises (mobility, sensorimotor, and vibration training) should be considered [6], which is in line with a growing body of literature, suggesting that physical exercise can reduce CIPN-induced symptoms and functional impairment [41-43].

\section{Therapy of CIPN-related neuropathic symptoms}

National and international guidelines provide recommendations for non-pharmacological as well as pharmacological treatment options of manifest CIPN. The pharmacological recommendations are summarized in Table 2 and specified for therapeutic procedures as well as advising expert societies. Overall, recommendations in current guidelines are mainly based on results from studies in patients suffering from other types of neuropathic pain such as postherpetic neuralgia, painful diabetic polyneuropathy, and post-surgical neuropathic pain or on studies specific for CIPN treatment but with lowquality medical evidence.

Conventional systemic treatment options for neuropathic pain include antiepileptic agents, antidepressants, including selective serotonin and norepinephrine reuptake inhibitors (SNRIs), and tricyclic antidepressants, as well as opioids. However, only the SNRI duloxetine is recommended for treatment of CIPN in existing guidelines [6, 7, 44], based on modest medical evidence for efficacy in one randomized, doubleblind, placebo-controlled CIPN-specific trial [45]. For all other systemic treatment options, clinical evidence in CIPN is still inconclusive (Table 2).

Systemic drugs need to be slowly titrated from a low starting dose to a dose providing best efficacy and limited side effects. Of special note in this context is the interaction potential of systemically acting substances in case of co-administration with chemotherapeutic and other therapies.

Topical treatment options for neuropathic pain and CIPN include the lidocaine patch (700 mg), the capsaicin patch (179 $\mathrm{mg}$ ), and various gel formulations.

\section{Non-pharmacological intervention}

The German S3 guideline for supportive therapy in oncology patients highly recommends functional exercises (balance, sensorimotor, and fine motor skill training) [6]. 


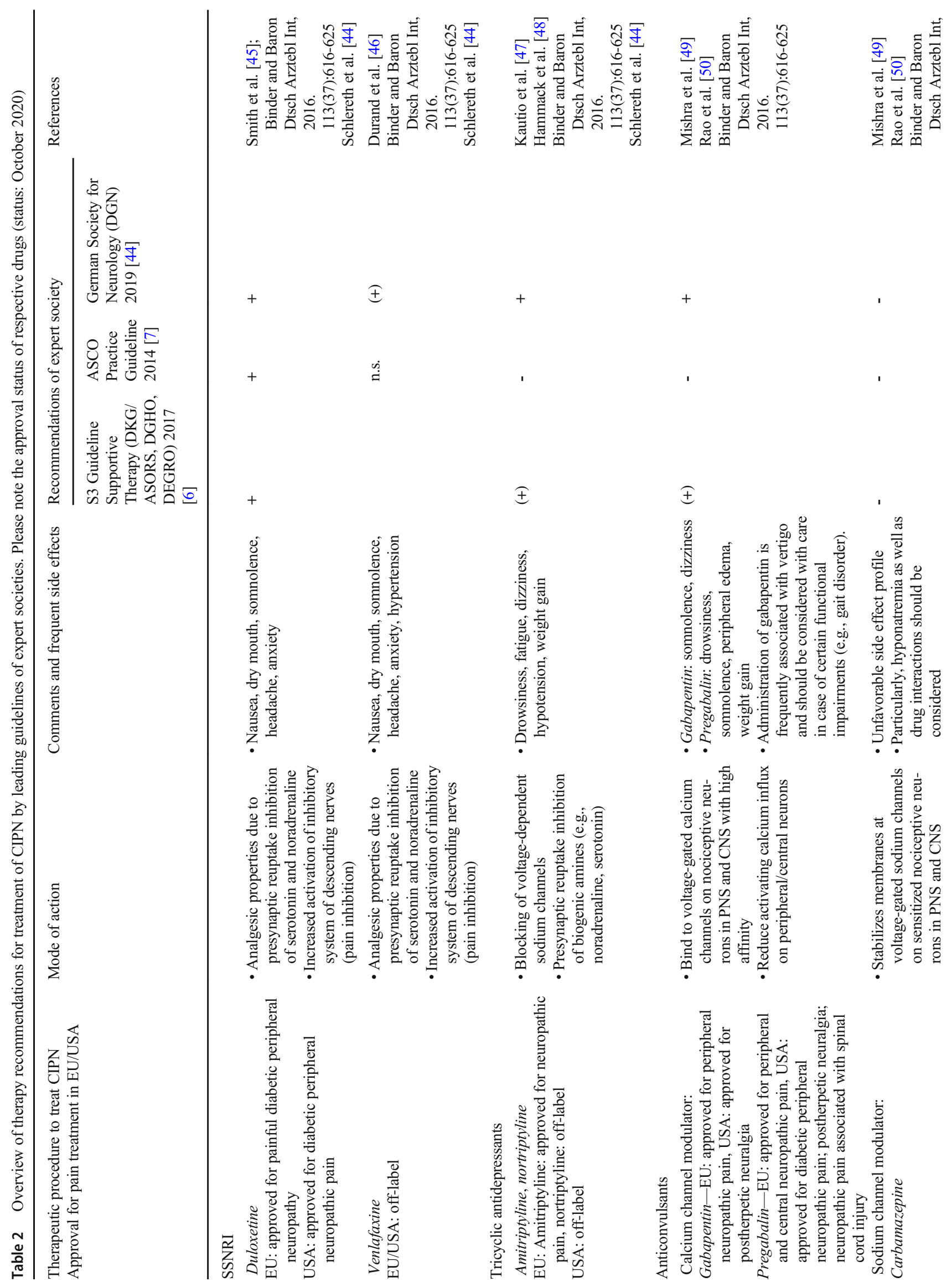




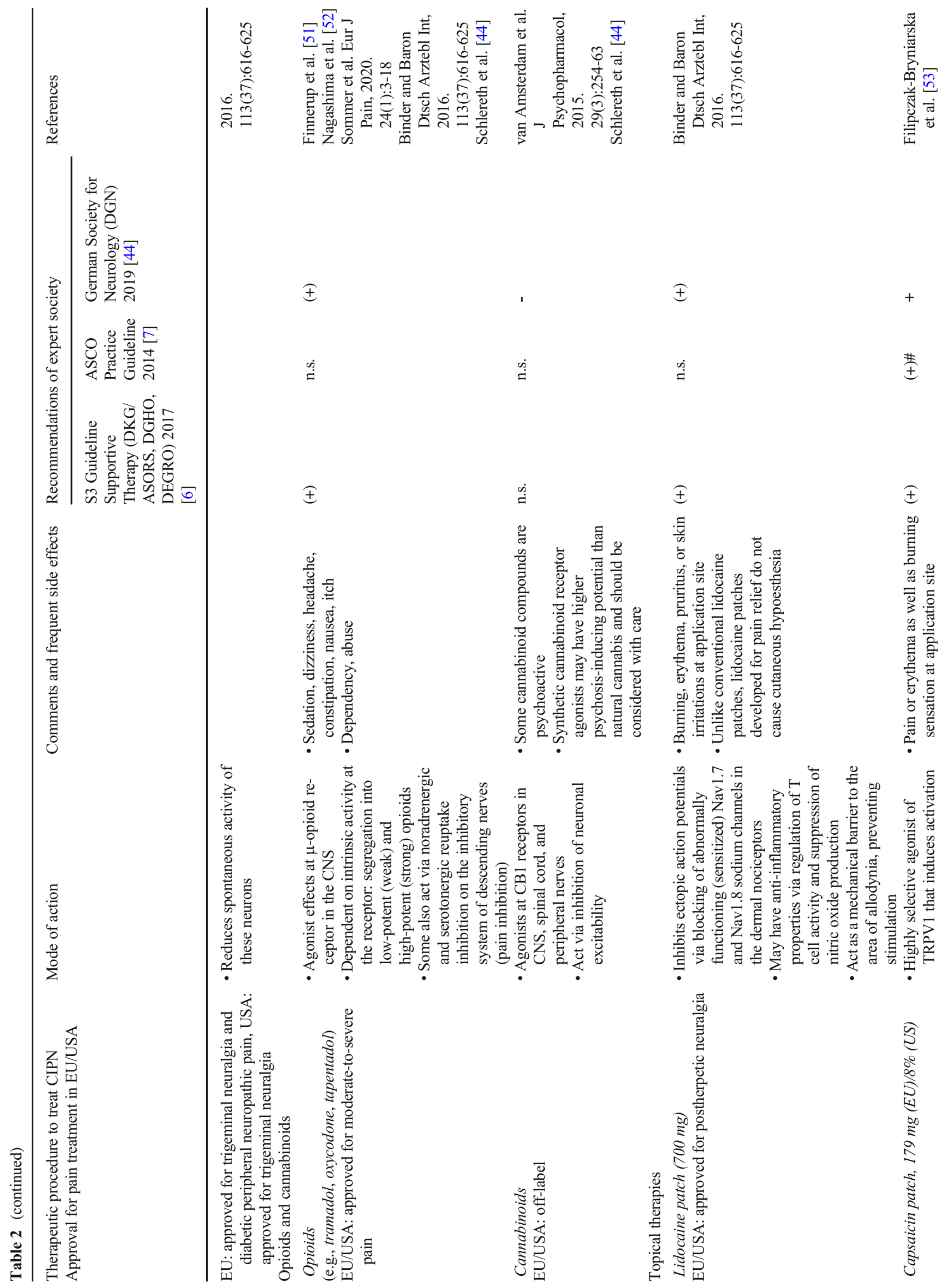




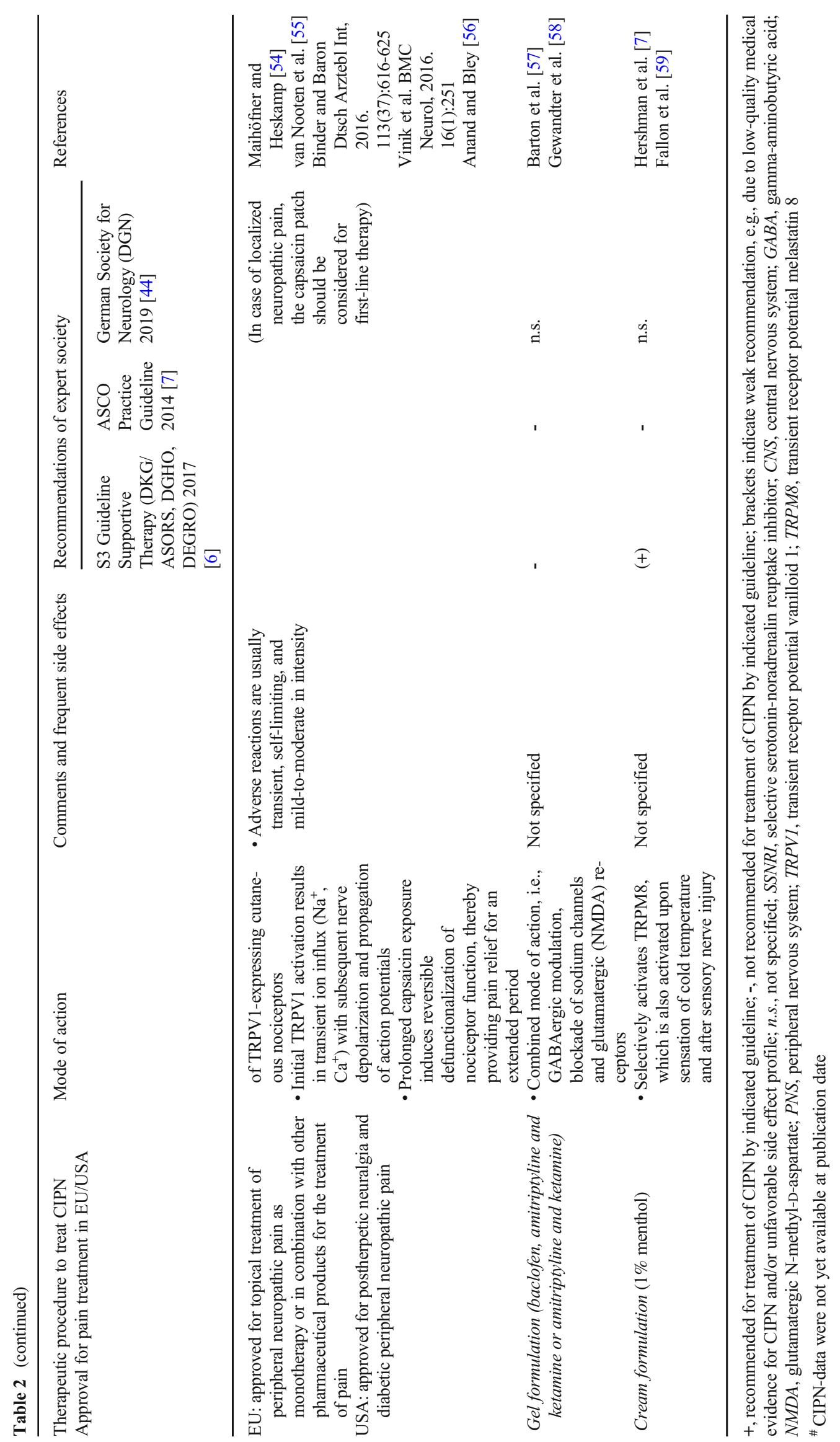




\section{Pharmacological intervention}

\section{Selective serotonin-noradrenalin reuptake inhibitor}

\section{Duloxetine}

In patients with peripheral neuropathy of other origin than CIPN, duloxetine is administered due to established efficacy. In addition, a phase III, randomized double-blind, placebocontrolled crossover study $(n=231)$ found that duloxetine treatment resulted in greater reduction of CIPN-associated pain, particularly when induced by platinum derivatives [45]. Based on these results, duloxetine is recommended for CIPN therapy $[6,7]$. However, potential drug interactions, particularly regarding the hepatic metabolism of duloxetine, should be considered for each individual patient.

\section{Venlafaxine}

Venlafaxine may be considered for CIPN therapy in individual cases $[6,44]$. The recommendation is based on data from a small study with a limited number of patients $(n=$ 24 ) indicating significant benefit vs. placebo, albeit occurrence of several side effects $[44,46]$. In addition, based on a recent comparative study, the administration of duloxetine seems to be more effective than venlafaxine in decreasing the symptoms of CIPN [60].

\section{Tricyclic antidepressants}

\section{Amitriptyline/nortriptyline}

Two randomized placebo-controlled studies of amitriptyline ( $n=114$ and $n=44$, respectively) revealed negative results or only discrete improvements of symptoms in CIPN patients [47, 61]. In addition, results of a phase III study regarding the use of nortriptyline in patients with cis-platinum-induced peripheral neuropathy $(n=51)$ revealed only modest and questionable benefit [48]. However, based on the limited options that are available for CIPN therapy and the demonstrated efficacy of these drugs in other neuropathic pain conditions, it is reasonable to try a tricyclic antidepressant [7]. Nevertheless, potential side effects, drug interactions, and cardiac toxicity should be considered upon risk-benefit analysis [44].

\section{Anticonvulsants}

\section{Gabapentin/pregabalin}

Although both gabapentin and pregabalin have been shown to be effective in the treatment of polyneuropathies, only limited scientific evidence for CIPN treatment exists. A phase III, randomized, double-blind, placebo-controlled crossover study of gabapentin in patients with CIPN $(n=115)$ revealed no improvement in either pain intensity or sensory neuropathy [50]. Pregabalin was shown to be superior to amitriptyline und gabapentin (as well as placebo) in a randomized cancer study with respect to neuropathic pain and side effects [49]. Common adverse reactions to pregabalin and gabapentin include dizziness, drowsiness, and somnolence; pregabalin is also more frequently associated with weight gain [51].

Similar to tricyclic antidepressant, gabapentin and pregabalin may be considered for CIPN treatment based on the limited therapeutic options and the demonstrated efficacy of these agents in other neuropathic pain conditions [6].

\section{Carbamazepine}

Carbamazepine cannot be recommended for treatment of neuropathic pain in general due to low evidence and frequent side effects. However, administration can be considered in single cases and is generally recommended in trigeminal neuralgia [44].

\section{Opioids}

Overall, the response of neuropathic pain to opioid therapy is low [51]. Administration of oxycodone during chemotherapy was associated with a lowered incidence of CIPN [52]. According to the German Society for Neurology, low- as well as high-potency opioids might be considered for treating neuropathic pain of any origin as third-line option, although side effects, development of tolerance, and misuse might be limiting [44].

\section{Non-opioid analgesics}

Non-opioid analgesics such as non-steroidal antiinflammatory drugs (NSAIDs), metamizole, or paracetamol display low efficacy in the treatment of neuropathic pain and are considered to be associated with a variety of potential side effects [6, 44]. However, peripheral nerve damage and neuropathic pain may arise from tissue pressure increase due to swelling of the feet and/or hands and has been described as a result of chronic venous insufficiency [62]. In these cases, NSAID therapy may be effective in reducing swelling and corresponding pain.

\section{Cannabinoids}

Clinical trials provide little medical evidence that cannabinoid-based medicines are effective for the treatment of neuropathic pain $[44,63]$. Data from a randomized, double-blind, placebo-controlled pilot study in 16 patients could also not support a substantial benefit of cannabinoids in 
treating CIPN [64]. According to the guideline of the German Society for Neurology, cannabinoids are not recommended for treatment of neuropathic pain of any origin as efficacy is low and the rate of side effects is high. In individual cases and upon failure of other therapeutic options, treatment with cannabinoids may be considered in the context of a multimodal pain therapy [44].

\section{Pharmacological intervention—-topical therapies}

\section{Patches}

\section{Lidocaine}

The lidocaine patch $(700 \mathrm{mg})$ is approved for the treatment of postherpetic neuralgia but have also been suggested by guidelines for the treatment of localized neuropathic pain of other origins, including CIPN $[6,44,65]$. However, randomized clinical trials proving efficacy in CIPN are missing to date [6]. Lidocaine patches might be used as second-line option for treatment of peripheral neuropathic pain, especially in case of intolerability of oral medications (e.g., in elderly patients) [44].

\section{Capsaicin}

In Europe, the capsaicin patch $(179 \mathrm{mg})$ is approved for topical treatment of peripheral neuropathic pain as monotherapy or in combination with other pharmaceutical products for pain treatment [66]. The guideline of the German Society for Neurology recommends the capsaicin $179 \mathrm{mg}$ patch for any kind of neuropathic pain as a second-line therapy. The effect is comparable to established oral medications with good tolerability and beneficial safety profile and low risk of systemic side effects [44, 55, 67]. Thus, for localized neuropathic pain, the guideline considers primary use [44]. Subgroup-specific data from 15 patients within the QUEPP study [54] support efficacy of the capsaicin patch specifically in CIPN (s. data below), which results in recommendation of the patch in respective guidelines (Table 2) [6]. Recently, the high-dose capsaicin patch was efficiently used for pain reduction in CIPN patients in two open-label single-center studies ( $n=18$ and $n=$ 16 , respectively) $[53,68]$. However, there is no recommendation for capsaicin treatment with low-dose formulations $(<$ $1 \%$ ) or in case of non-painful polyneuropathies [6].

\section{Gel and cream formulation}

I. Baclofen (0.8\%), amitriptyline (3\%) and ketamine (1.5\%)/ amitriptyline (4\%), and ketamine (2\%)

Topical therapy of CIPN with a gel formulation containing baclofen $(0.8 \%)$, amitriptyline (3\%), and ketamine $(1.5 \%)$ may be suggested as it was beneficial in comparison to placebo in a randomized, double-blind, placebo-controlled trial in 208 CIPN patients. However, the overall effect was modest and not clinically relevant [57]. Furthermore, the gel is not available, and type and composition are unknown [6]. A clinical study with topical amitriptyline (4\%) and ketamine (2\%) twice daily for 6 days in 462 cancer survivors with CIPN revealed no significant effect on pain, numbness, or tingling [58].

\section{Menthol (1\%)}

Significant reduction of pain as well as some improvement in functionality and sensitivity was detected upon topical therapy of CIPN with $1 \%$ menthol in a proof-of-concept study with 51 patients. However, the patient cohort was small, and the study was non-blinded [59].

\section{Current evidence for topical treatment of CIPN with capsaicin $179 \mathrm{mg}$ patch}

Capsaicin is a highly selective agonist of the transient receptor potential vanilloid 1 (TRPV1) ion channel and induces activation of TRPV1-expressing cutaneous nociceptors. Upon activation, TRPV1 opens transiently resulting in an ion influx $\left(\mathrm{Na}^{+}, \mathrm{Ca}^{+}\right)$with subsequent release of vasoactive neuropeptides, depolarization, and propagation of action potentials into spinal cord and brain. Patients may experience this as various sensations at the application site (warming, burning, stinging, or itching) [56]. Importantly, while environmental or inflammatory stimuli result in transient TRPV1 activation, prolonged exposure of the chemically stable capsaicin induces a cascade of cellular events (e.g., cytoskeleton breakdown and loss of mitochondrial function) that result in reversible nociceptor defunctionalization within the (painful) application area, providing control of localized neuropathic pain symptoms for an average of 5 months $[56,69]$. Treatment with the capsaicin patch may be repeated every 3 months or later as needed [66]. Re-treatment after 2 months is possible for individual patients after careful assessment by the physician. Interestingly, with multiple applications, pain reduction can steadily increase with each application and re-treatment times can get longer [70, 71].

Exposure to the capsaicin $179 \mathrm{mg}$ patch reduced the density of epidermal nerve fibers (ENF) and induced modest but significant changes in tactile thresholds as well as sharp mechanical pain detection in healthy volunteers. Tactile and sharp pain sensations returned to normal within 12 weeks after application, and ENF density was regenerated 24 weeks after exposure. The latter suggests that the proximal dermal origins of ENFs remained intact and that only the distal dermal nerve segments and epidermal nerve endings are affected [72].

Data from a CIPN subgroup $(n=15)$ within the open-label, clinical observational QUEPP study [54] point to similar 
efficacy results in comparison to the total study population ( $n$ $=1044$ patients with various peripheral neuropathic pain conditions). The average pain intensity assessed by the 11-point numeric pain rating scale (NPRS) continuously decreased over the course of the study (Fig. 3a); a reduction of pain intensity for $\geq 30 \%$ was achieved in $46.7 \%$ of the CIPN patients, and pain reduction $\geq 50 \%$ was reported for $33.3 \%$ of the CIPN patients [73, 74]. Tolerability was accessed as either "very good" or "good" by $80 \%$ of the treating physicians (supplemental figure 1). In addition, therapy with the capsaicin patch also improved symptoms typically associated with neuropathic pain, including tingling and burning sensation, thermal hyperesthesia (especially cold sensitivity), and numbness (Fig. 3b). Thus, although the evidence is low due to the small number of participants, the results for CIPN patients are similar to those of the overall QUEPP study population.

Analyses of the total QUEPP population $(n=1.044)$ revealed that the analgesic effect of the capsaicin patch is higher and lasts longer in patients with shorter durations of preexisting neuropathic pain. The highest response to
Fig. 3 a Average pain intensity (NPRS 0-10 scores) before and within 12 weeks after single treatment with the capsaicin $179 \mathrm{mg}$ patch in patients with CIPN-related pain (dark blue) and in the total study population (light blue; peripheral neuropathic pain of different etiologies). The absolute change between the mean NPRS scores at baseline and week $1-2$ to week 12 was -2.4 (0.4 SEM, $p \leq 0.001$, paired $t$ test) for CIPN patients and - $1.7(0.1$ SEM, $p \leq 0.001$, paired $t$ test) for the total QUEPP study population. NPRS $=$ numeric pain rating scale; $\mathrm{SEM}=$ standard error of the mean. b Mean scores of intensity of sensory symptoms between baseline and the end of the observational period at week 12 in CIPN patients assessed with the painDETECT® questionnaire. For each symptom, single scores were assessed (never, 0; hardly noticed, 1 ; slightly, 2; moderately, 3 ; strongly, 4; very strongly, 5) at baseline and after 12 weeks. Relative changes of symptoms $(\%)$ are shown within the bars (mean, SEM). Baseline score $>0$; SEM $=$ standard error of the mean. Modified from [73] a

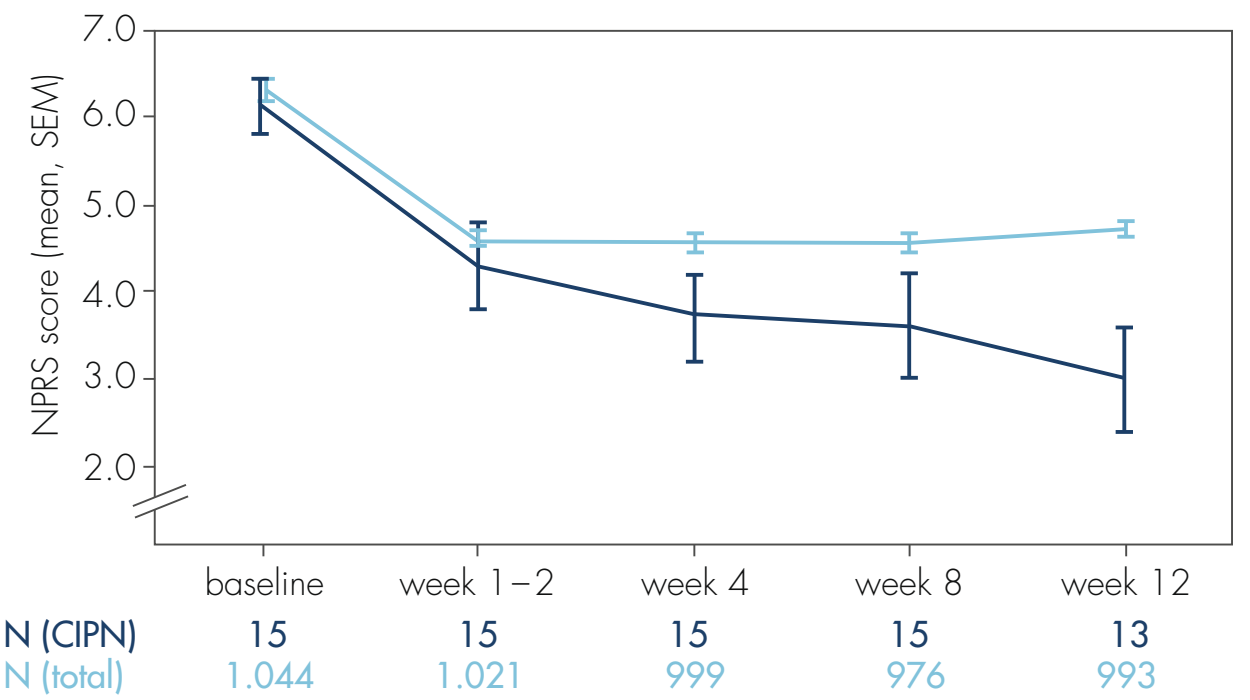

b

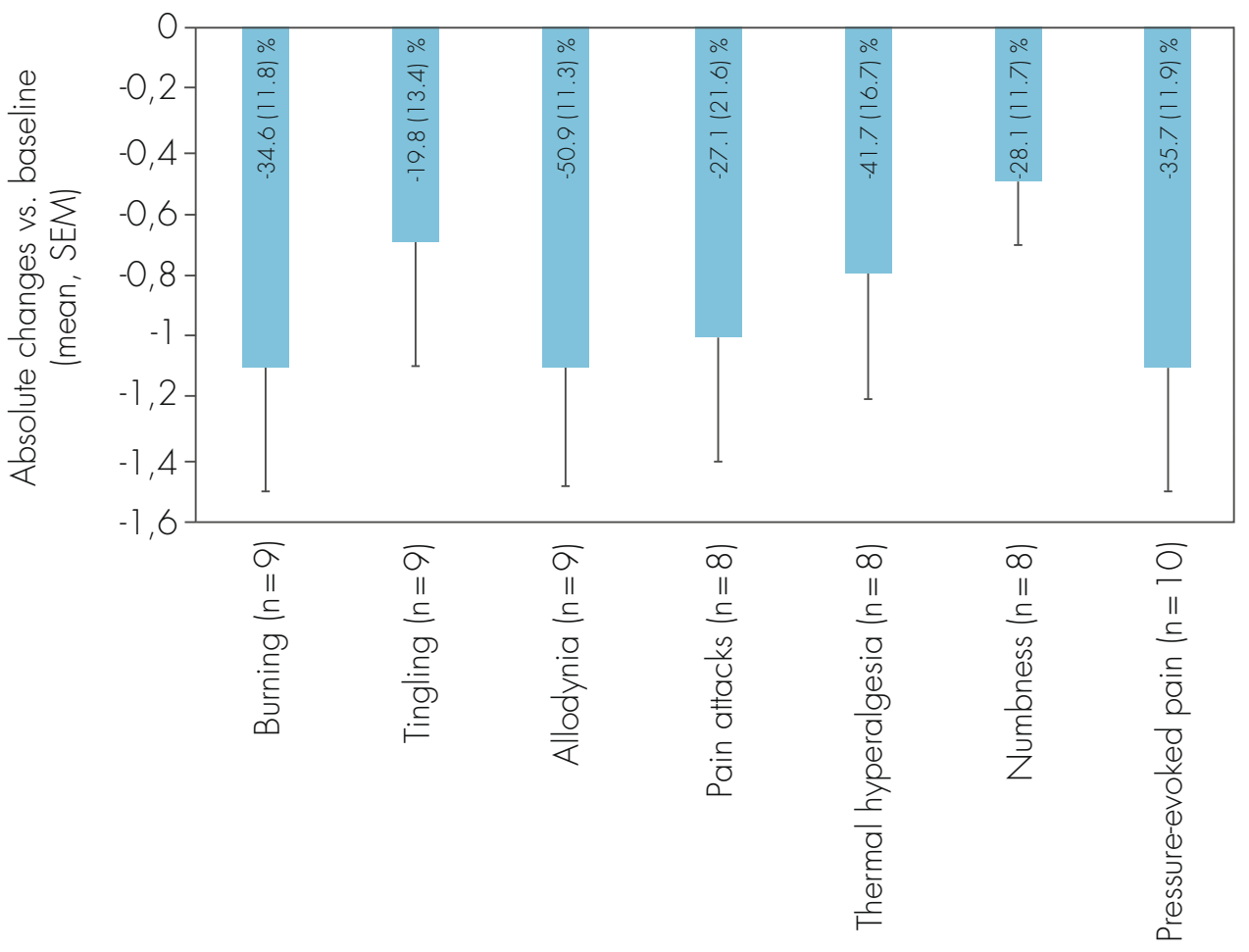


capsaicin treatment was achieved within 6 months of onset of peripheral neuropathic pain. Therefore, treatment should be initialized as early as possible [75].

Data from a small single-center study with 18 patients suffering from oxaliplatin-induced neuropathy also confirmed efficacy of the capsaicin 179-mg patch in pain reduction [53]. Interestingly, recent data reveal even further properties of capsaicin beyond significant reduction of CIPN-related neuropathic pain: The study published by Anand et al. suggests a disease-modifying property of capsaicin therapy via regeneration and phenotypical restoration of sensory nerve fibers in CIPN patients in remission after chemotherapy [68]. This was demonstrated by skin biopsy and detailed immunohistochemical analyses before and after capsaicin treatment. It has been suggested that the capsaicin-induced defunctionalization of abnormal nerve fibers may support subsequent nerve regeneration.

\section{Treatment algorithm for clinical practice}

Treatment of diagnosed CIPN should address the symptoms with the highest impact on patients' QoL. It appears reasonable to distinguish between neuropathic pain and functional impairment without pronounced pain symptoms. A treatment algorithm for CIPN therapy in clinical practice is proposed in Fig. 4. If pain is the major reason for deteriorated QoL, pharmaceutical treatment options are appropriate, while functional impairment without severe or limiting pain is reasonably treated with physiotherapeutic methods. However, since individual patients might simultaneously be affected by pain and functional impairment, combination therapies are feasible. In addition, since CIPN-mediated symptoms are typically located in hands and/or feet, it is reasonable to consider a local treatment option in the first place [44].

Since systemic therapies might be accompanied by systemic interactions and side effects, the choice of therapy should be influenced by comorbidities and co-medications. Of special note in this context is the administration of pregabalin or gabapentin in patients with sensory ataxia (especially in case of non-significant pain symptoms) as these drugs might induce dizziness and subsequently increase the risk of falling.

Consequently, and in view of patients with comorbidities or at risk of cancer recurrence, topical treatment options with a non-systemic mode of action should be preferred for patients with CIPN-associated pain due to the low rate of systemic side effects and systemic drug interactions.
Fig. 4 Treatment criteria for clinical practice upon CIPN diagnosis. Please note off-label use for treatment of CIPN in EU $(*) /$ USA $\left(^{*}\right)$ (for details, see Table 2)

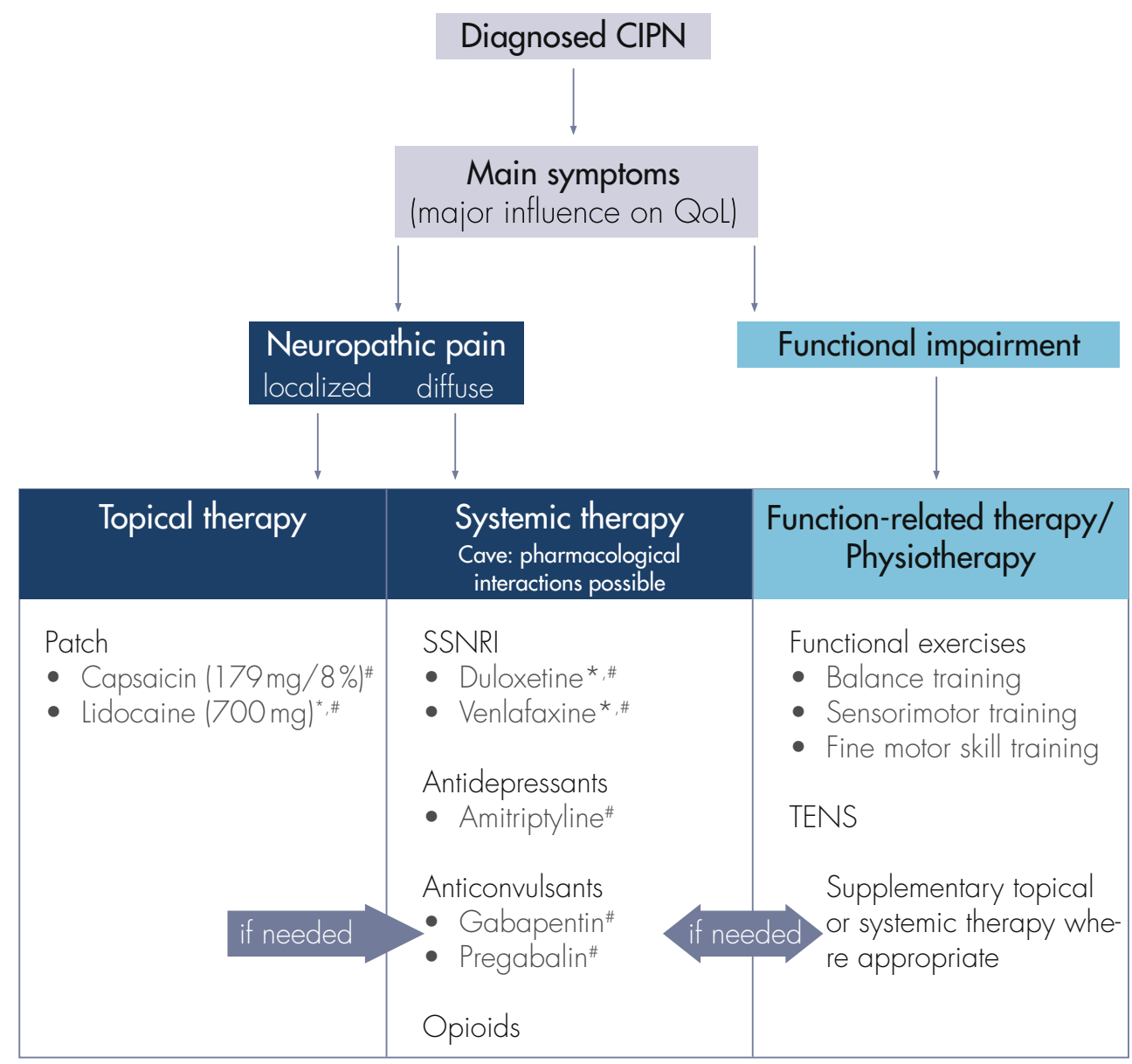




\section{Conclusion}

CIPN represents a major concern in cancer therapy. There is limited evidence-based data available for prophylaxis and treatment of this condition. Early start of functional exercises during chemotherapy is recommended.

Existing data on pharmaceutical treatment of CIPN allow weak recommendations for duloxetine. Given the paucity of available alternative treatment strategies and extrapolating efficacy data from other neuropathic pain conditions, certain antidepressants (amitriptyline), and anticonvulsants (gabapentin, pregabalin) may be considered. If appropriate, opioids may be used on the basis of clinician's experience.

Systemic treatments are associated with a typical tolerability profile and carry the risk of drug interactions. Study results from open-label trials provide evidence for successful topical treatment of CIPN with capsaicin $179 \mathrm{mg}$ patch. The patch provides significant reduction of CIPN-related pain and symptoms as shown in the literature for other neuropathic disorders, while displaying low rates of side effects $[54,67,70]$. In particular, systemic side effects and drug interactions can be reduced or avoided. In addition, recent data point to promising disease-modifying effects of the capsaicin patch [68].

Supplementary Information The online version contains supplementary material available at https://doi.org/10.1007/s00520-021-06042-x.

Code availability Not applicable.

Authors' contribution C.M. and R.B.: Drafting, revision, and approval of the manuscript, involved in data generation within the QUEPP study

I.D., H.T.: Drafting, revision, and approval of the article

T.Q.: Conception and writing of the manuscript

Funding The publication was funded by Grünenthal. Editorial assistance for the writing of this article was provided by Carmen Koch-Stork, $\mathrm{PhD}$, KW medipoint, and was funded by Grünenthal GmbH. The authors retained full editorial control over the content of the article.

Data availability Data sharing is not applicable to this article as no datasets were generated or analyzed during the current study.

\section{Declarations}

Ethics approval Not applicable.

Consent to participate Not applicable.

Consent for publication Not applicable.

Conflict of interest In the past 3 years, C.M. has worked as a consultant and/or speaker for the following companies: Allergan, Bionorica, Grünenthal, GSK, Lilly, Novartis, Daiichi Sankyo.

H.T. received honoraria from Grünenthal.
I.D. has worked as a consultant in the last 3 years for Amgen, MSD, TEVA, Grünenthal, Clovis, and Hexal. He received honoraria from the companies above as well as Roche and GSK.

T.Q. is a salaried employee of Grünenthal.

In the past years, R. B. has worked as a consultant and/or speaker for the following companies: Pfizer Pharma $\mathrm{GmbH}$; Genzyme GmbH; Grünenthal $\mathrm{GmbH}$; Mundipharma Research $\mathrm{GmbH}$ und Co., KG; Allergan; Sanofi Pasteur; Medtronic; Eisai; Lilly GmbH; Boehringer Ingelheim Pharma GmbH \& Co., KG; Astellas Pharma GmbH; Novartis Pharma GmbH, Bristol-Myers Squibb, Biogenidec, AstraZeneca GmbH, Merck, Abbvie, Bayer-Scherin; MSD GmbH; Daiichi Sankyo; Glenmark Pharmaceuticals S.A.; Seqirus Australia Pty., Ltd.; Teva Pharmaceuticals Europe Niederlande; Teva GmbH; Genentech; Mundipharma International Ltd., UK; Astellas Pharma Ltd., UK; TAD Pharma GmbH; Galapagos NV; Kyowa Kirin GmbH; Vertex Pharmaceuticals Inc.; Biotest AG; Celgene GmbH; Desitin Arzneimittel GmbH; Regeneron Pharmaceuticals Inc., USA; Theranexus DSV CEA Frankreich; Grünenthal SA Portugal; Abbott Products Operations AG Schweiz; Bayer AG; Grünenthal Pharma AG Schweiz; Mundipharma Research Ltd., UK; Akcea Therapeutics Germany GmbH; Asahi Kasei Pharma Corporation; AbbVie Deutschland GmbH \& Co. KG; Air Liquide Sante International Frankreich; Alnylam Germany GmbH; Lateral Pharma Pty Ltd.; Hexal AG; Ethos Srl Italien; Janssen; SanofiAventis Deutschland GmbH; Agentur Brigitte Süss; Grünenthal B.V. Niederlande.

Open Access This article is licensed under a Creative Commons Attribution 4.0 International License, which permits use, sharing, adaptation, distribution and reproduction in any medium or format, as long as you give appropriate credit to the original author(s) and the source, provide a link to the Creative Commons licence, and indicate if changes were made. The images or other third party material in this article are included in the article's Creative Commons licence, unless indicated otherwise in a credit line to the material. If material is not included in the article's Creative Commons licence and your intended use is not permitted by statutory regulation or exceeds the permitted use, you will need to obtain permission directly from the copyright holder. To view a copy of this licence, visit http://creativecommons.org/licenses/by/4.0/.

\section{References}

1. Jensen TS, Baron R, Haanpää M, Kalso E, Loeser JD, Rice ASC, Treede RD (2011) A new definition of neuropathic pain. Pain 152(10):2204-2205

2. Scholz J, Finnerup NB, Attal N, Aziz Q, Baron R, Bennett MI, Benoliel R, Cohen M, Cruccu G, Davis KD, Evers S, First M, Giamberardino MA, Hansson P, Kaasa S, Korwisi B, Kosek E, Lavand'homme P, Nicholas M, Nurmikko T, Perrot S, Raja SN, Rice ASC, Rowbotham MC, Schug S, Simpson DM, Smith BH, Svensson P, Vlaeyen JWS, Wang SJ, Barke A, Rief W, Treede RD, Classification Committee of the Neuropathic Pain Special Interest Group (NeuPSIG) (2019) The IASP classification of chronic pain for ICD-11: chronic neuropathic pain. Pain 160(1):53-59

3. Edwards HL, Mulvey MR, Bennett MI (2019) Cancer-related neuropathic pain. Cancers (Basel) 11(3)

4. Cioroiu C, Weimer LH (2017) Update on chemotherapy-induced peripheral neuropathy. Curr Neurol Neurosci Rep 17(6):47

5. Hausheer FH, Schilsky RL, Bain S, Berghorn EJ, Lieberman F (2006) Diagnosis, management, and evaluation of chemotherapyinduced peripheral neuropathy. Semin Oncol 33(1):15-49 
6. Supportive therapy in oncology patients, S3-level guideline of the Deutsche Krebsgesellschaft, Deutsche Krebshilfe, AWMF: [Supportive Therapie bei onkologischen PatientInnen Langversion 1.3, Februar 2020], AWMF Registry Number 032/ $054 \mathrm{OL}$. Access date: $06 / 19 / 2020 ; \mathrm{https}: / / \mathrm{www}$. leitlinienprogramm-onkologie.de/leitlinien/supportive-therapie/ 2020

7. Hershman DL, Lacchetti C, Dworkin RH, Lavoie Smith EM, Bleeker J, Cavaletti G, Chauhan C, Gavin P, Lavino A, Lustberg MB, Paice J, Schneider B, Smith ML, Smith T, Terstriep S, Wagner-Johnston N, Bak K, Loprinzi CL, American Society of Clinical Oncology (2014) Prevention and management of chemotherapy-induced peripheral neuropathy in survivors of adult cancers: American Society of Clinical Oncology clinical practice guideline. J Clin Oncol 32(18):1941-1967

8. Sprauten M, Darrah TH, Peterson DR, Campbell ME, Hannigan RE, Cvancarova M, Beard C, Haugnes HS, Fosså SD, Oldenburg J, Travis LB (2012) Impact of long-term serum platinum concentrations on neuro- and ototoxicity in cisplatin-treated survivors of testicular cancer. J Clin Oncol 30(3):300-307

9. Beijers AJ, Mols F, Vreugdenhil G (2014) A systematic review on chronic oxaliplatin-induced peripheral neuropathy and the relation with oxaliplatin administration. Support Care Cancer 22(7):19992007

10. Attal N, Bouhassira D, Gautron M, Vaillant JN, Mitry E, Lepère C, Rougier P, Guirimand F (2009) Thermal hyperalgesia as a marker of oxaliplatin neurotoxicity: a prospective quantified sensory assessment study. Pain 144(3):245-252

11. Boyette-Davis JA, Hou S, Abdi S, Dougherty PM (2018) An updated understanding of the mechanisms involved in chemotherapyinduced neuropathy. Pain Manag 8(5):363-375

12. Ma J, Kavelaars A, Dougherty PM, Heijnen CJ (2018) Beyond symptomatic relief for chemotherapy-induced peripheral neuropathy: targeting the source. Cancer 124(11):2289-2298

13. Staff NP et al (2017) Chemotherapy-induced peripheral neuropathy: a current review. Ann Neurol 81(6):772-781

14. Rivera DR et al (2018) Chemotherapy-associated peripheral neuropathy in patients with early-stage breast cancer: a systematic review. J Natl Cancer Inst 110(2)

15. Starobova H, Vetter I (2017) Pathophysiology of chemotherapyinduced peripheral neuropathy. Front Mol Neurosci 10:174

16. Gießen-Jung C, von Baumgarten L (2018) Chemotherapieinduzierte periphere Neuropathie [Peripheral neuropathy as a side effect of chemotherapy and targeted therapy]. Dtsch Med Wochenschr 113(13):970-978

17. Park SB, Goldstein D, Krishnan AV, Lin CS, Friedlander ML, Cassidy J, Koltzenburg M, Kiernan MC (2013) Chemotherapyinduced peripheral neurotoxicity: a critical analysis. CA Cancer J Clin 63(6):419-437

18. Addington J, Freimer M (2016) Chemotherapy-induced peripheral neuropathy: an update on the current understanding. F1000Res 5

19. Miltenburg NC, Boogerd W (2014) Chemotherapy-induced neuropathy: a comprehensive survey. Cancer Treat Rev 40(7):872-882

20. Seretny M, Currie GL, Sena ES, Ramnarine S, Grant R, MacLeod MR, Colvin LA, Fallon M (2014) Incidence, prevalence, and predictors of chemotherapy-induced peripheral neuropathy: a systematic review and meta-analysis. Pain 155(12):2461-2470

21. Beijers A, Mols F, Dercksen W, Driessen C, Vreugdenhil G (2014) Chemotherapy-induced peripheral neuropathy and impact on quality of life 6 months after treatment with chemotherapy. J Community Support Oncol 12(11):401-406

22. Bandos $\mathrm{H}$ et al (2018) Long-term peripheral neuropathy in breast cancer patients treated with adjuvant chemotherapy: NRG oncology/NSABP B-30. J Natl Cancer Inst 110(2)

23. Briani C, Argyriou AA, Izquierdo C, Velasco R, Campagnolo M, Alberti P, Frigeni B, Cacciavillani M, Bergamo F, Cortinovis D,
Cazzaniga M, Bruna J, Cavaletti G, Kalofonos HP (2014) Longterm course of oxaliplatin-induced polyneuropathy: a prospective 2-year follow-up study. J Peripher Nerv Syst 19(4):299-306

24. Miaskowski C, Mastick J, Paul SM, Topp K, Smoot B, Abrams G, Chen LM, Kober KM, Conley YP, Chesney M, Bolla K, Mausisa G, Mazor M, Wong M, Schumacher M, Levine JD (2017) Chemotherapy-induced neuropathy in cancer survivors. J Pain Symptom Manag 54(2):204-218 e2

25. Kolb NA, Smith AG, Singleton JR, Beck SL, Stoddard GJ, Brown S, Mooney K (2016) The association of chemotherapy-induced peripheral neuropathy symptoms and the risk of falling. JAMA Neurol 73(7):860-866

26. Mols F, Beijers T, Vreugdenhil G, van de Poll-Franse L (2014) Chemotherapy-induced peripheral neuropathy and its association with quality of life: a systematic review. Support Care Cancer 22(8):2261-2269

27. Basch E, Iasonos A, McDonough T, Barz A, Culkin A, Kris MG, Scher HI, Schrag D (2006) Patient versus clinician symptom reporting using the National Cancer Institute Common Terminology Criteria for Adverse Events: results of a questionnaire-based study. Lancet Oncol 7(11):903-909

28. Nyrop KA, Deal AM, Reeder-Hayes KE, Shachar SS, Reeve BB, Basch E, Choi SK, Lee JT, Wood WA, Anders CK, Carey LA, Dees EC, Jolly TA, Kimmick GG, Karuturi MS, Reinbolt RE, Speca JEC, Muss HB (2019) Patient-reported and clinicianreported chemotherapy-induced peripheral neuropathy in patients with early breast cancer: current clinical practice. Cancer 125(17): 2945-2954

29. Zhi WI, Chen P, Kwon A, Chen C, Harte SE, Piulson L, Li S, Patil S, Mao JJ, Bao T (2019) Chemotherapy-induced peripheral neuropathy (CIPN) in breast cancer survivors: a comparison of patientreported outcomes and quantitative sensory testing. Breast Cancer Res Treat 178(3):587-595

30. Baron R, Binder A, Wasner G (2010) Neuropathic pain: diagnosis, pathophysiological mechanisms, and treatment. Lancet Neurol 9(8):807-819

31. Postma TJ, Aaronson NK, Heimans JJ, Muller MJ, Hildebrand JG, Delattre JY, Hoang-Xuan K, Lantéri-Minet M, Grant R, Huddart R, Moynihan C, Maher J, Lucey R, EORTC Quality of Life Group (2005) The development of an EORTC quality of life questionnaire to assess chemotherapy-induced peripheral neuropathy: the QLQCIPN20. Eur J Cancer 41(8):1135-1139

32. Cavaletti G, Frigeni B, Lanzani F, Piatti M, Rota S, Briani C, Zara G, Plasmati R, Pastorelli F, Caraceni A, Pace A, Manicone M, Lissoni A, Colombo N, Bianchi G, Zanna C, Italian NETox Group (2007) The Total Neuropathy Score as an assessment tool for grading the course of chemotherapy-induced peripheral neurotoxicity: comparison with the National Cancer Institute-Common Toxicity Scale. J Peripher Nerv Syst 12(3):210-215

33. Cavaletti G, Frigeni B, Lanzani F, Mattavelli L, Susani E, Alberti P, Cortinovis D, Bidoli P (2010) Chemotherapy-induced peripheral neurotoxicity assessment: a critical revision of the currently available tools. Eur J Cancer 46(3):479-494

34. Freynhagen R, Baron R, Gockel U, Tölle TR (2006) painDETECT: a new screening questionnaire to identify neuropathic components in patients with back pain. Curr Med Res Opin 22(10):1911-1920

35. Bouhassira D, Attal N, Alchaar H, Boureau F, Brochet B, Bruxelle J, Cunin G, Fermanian J, Ginies P, Grun-Overdyking A, JafariSchluep H, Lantéri-Minet M, Laurent B, Mick G, Serrie A, Valade D, Vicaut E (2005) Comparison of pain syndromes associated with nervous or somatic lesions and development of a new neuropathic pain diagnostic questionnaire (DN4). Pain 114(1-2): 29-36

36. Lauria G, Devigili G (2007) Skin biopsy as a diagnostic tool in peripheral neuropathy. Nat Clin Pract Neurol 3(10):546-557 
37. Tang Z, Chen Z, Tang B, Jiang H (2015) Primary erythromelalgia: a review. Orphanet J Rare Dis 10:127

38. Kachrani R et al (2020) Chemotherapy-induced peripheral neuropathy: causative agents, preventative strategies, and treatment approaches. J Pain Palliat Care Pharmacother:1-12

39. Beijers AJM, Bonhof CS, Mols F, Ophorst J, de Vos-Geelen J, Jacobs EMG, van de Poll-Franse LV, Vreugdenhil G (2020) Multicenter randomized controlled trial to evaluate the efficacy and tolerability of frozen gloves for the prevention of chemotherapy-induced peripheral neuropathy. Ann Oncol 31(1): 131-136

40. Hanai A, Ishiguro H, Sozu T, Tsuda M, Yano I, Nakagawa T, Imai S, Hamabe Y, Toi M, Arai H, Tsuboyama T (2018) Effects of cryotherapy on objective and subjective symptoms of paclitaxelinduced neuropathy: prospective self-controlled trial. J Natl Cancer Inst 110(2):141-148

41. Duregon F, Vendramin B, Bullo V, Gobbo S, Cugusi L, di Blasio A, Neunhaeuserer D, Zaccaria M, Bergamin M, Ermolao A (2018) Effects of exercise on cancer patients suffering chemotherapyinduced peripheral neuropathy undergoing treatment: a systematic review. Crit Rev Oncol Hematol 121:90-100

42. Kleckner IR, Kamen C, Gewandter JS, Mohile NA, Heckler CE, Culakova E, Fung C, Janelsins MC, Asare M, Lin PJ, Reddy PS, Giguere J, Berenberg J, Kesler SR, Mustian KM (2018) Effects of exercise during chemotherapy on chemotherapy-induced peripheral neuropathy: a multicenter, randomized controlled trial. Support Care Cancer 26(4):1019-1028

43. Zimmer P, Trebing S, Timmers-Trebing U, Schenk A, Paust R, Bloch W, Rudolph R, Streckmann F, Baumann FT (2018) Eightweek, multimodal exercise counteracts a progress of chemotherapyinduced peripheral neuropathy and improves balance and strength in metastasized colorectal cancer patients: a randomized controlled trial. Support Care Cancer 26(2):615-624

44. Schlereth T et al (2019) Diagnosis and non-interventional therapy of neuropathic pain [Diagnose und nicht interventionelle Therapie neuropathischer Schmerzen]; S2k-level guideline of the Deutsche Gesellschaft für Neurologie; Guidelines for Diagnostics and Therapy in Neurology. Access date: 11/13/2019; https://www. dgn.org/leitlinien

45. Smith EM et al (2013) Effect of duloxetine on pain, function, and quality of life among patients with chemotherapy-induced painful peripheral neuropathy: a randomized clinical trial. JAMA 309(13): 1359-1367

46. Durand JP, Deplanque G, Montheil V, Gornet JM, Scotte F, Mir O, Cessot A, Coriat R, Raymond E, Mitry E, Herait P, Yataghene Y, Goldwasser F (2012) Efficacy of venlafaxine for the prevention and relief of oxaliplatin-induced acute neurotoxicity: results of EFFOX, a randomized, double-blind, placebo-controlled phase III trial. Ann Oncol 23(1):200-205

47. Kautio AL, Haanpää M, Saarto T, Kalso E (2008) Amitriptyline in the treatment of chemotherapy-induced neuropathic symptoms. J Pain Symptom Manag 35(1):31-39

48. Hammack JE, Michalak JC, Loprinzi CL, Sloan JA, Novotny PJ, Soori GS, Tirona MT, Rowland KM, Stella PJ, Johnson JA (2002) Phase III evaluation of nortriptyline for alleviation of symptoms of cis-platinum-induced peripheral neuropathy. Pain 98(1-2):195-203

49. Mishra S, Bhatnagar S, Goyal GN, Rana SPS, Upadhya SP (2012) A comparative efficacy of amitriptyline, gabapentin, and pregabalin in neuropathic cancer pain: a prospective randomized double-blind placebo-controlled study. Am J Hosp Palliat Care 29(3):177-182

50. Rao RD, Michalak JC, Sloan JA, Loprinzi CL, Soori GS, Nikcevich DA, Warner DO, Novotny P, Kutteh LA, Wong GY, and the North Central Cancer Treatment Group (2007) Efficacy of gabapentin in the management of chemotherapy-induced peripheral neuropathy: a phase 3 randomized, double-blind, placebo-controlled, crossover trial (N00C3). Cancer 110(9):2110-2118
51. Finnerup NB, Attal N, Haroutounian S, McNicol E, Baron R, Dworkin RH, Gilron I, Haanpää M, Hansson P, Jensen TS, Kamerman PR, Lund K, Moore A, Raja SN, Rice ASC, Rowbotham M, Sena E, Siddall P, Smith BH, Wallace M (2015) Pharmacotherapy for neuropathic pain in adults: a systematic review and meta-analysis. Lancet Neurol 14(2):162-173

52. Nagashima M, Ooshiro M, Moriyama A, Sugishita Y, Kadoya K, Sato A, Kitahara T, Takagi R, Urita T, Yoshida Y, Tanaka H, Oshiro T, Okazumi S, Katoh R (2014) Efficacy and tolerability of controlled-release oxycodone for oxaliplatin-induced peripheral neuropathy and the extension of FOLFOX therapy in advanced colorectal cancer patients. Support Care Cancer 22(6):1579-1584

53. Filipczak-Bryniarska I, Krzyzewski RM, Kucharz J, MichalowskaKaczmarczyk A, Kleja J, Woron J, Strzepek K, Kazior L, Wordliczek J, Grodzicki T, Krzemieniecki K (2017) High-dose $8 \%$ capsaicin patch in treatment of chemotherapy-induced peripheral neuropathy: single-center experience. Med Oncol 34(9):162

54. Maihöfner C, Heskamp ML (2013) Prospective, non-interventional study on the tolerability and analgesic effectiveness over 12 weeks after a single application of capsaicin 8\% cutaneous patch in 1044 patients with peripheral neuropathic pain: first results of the QUEPP study. Curr Med Res Opin 29(6):673-683

55. van Nooten F, Treur M, Pantiri K, Stoker M, Charokopou M (2017) Capsaicin 8\% patch versus oral neuropathic pain medications for the treatment of painful diabetic peripheral neuropathy: a systematic literature review and network meta-analysis. Clin Ther 39(4):787803 e 18

56. Anand P, Bley K (2011) Topical capsaicin for pain management: therapeutic potential and mechanisms of action of the new highconcentration capsaicin 8\% patch. Br J Anaesth 107(4):490-502

57. Barton DL, Wos EJ, Qin R, Mattar BI, Green NB, Lanier KS, Bearden JD III, Kugler JW, Hoff KL, Reddy PS, Rowland KM Jr, Riepl M, Christensen B, Loprinzi CL (2011) A double-blind, placebo-controlled trial of a topical treatment for chemotherapyinduced peripheral neuropathy: NCCTG trial N06CA. Support Care Cancer 19(6):833-841

58. Gewandter JS, Mohile SG, Heckler CE, Ryan JL, Kirshner JJ, Flynn PJ, Hopkins JO, Morrow GR (2014) A phase III randomized, placebo-controlled study of topical amitriptyline and ketamine for chemotherapy-induced peripheral neuropathy (CIPN): a University of Rochester CCOP study of 462 cancer survivors. Support Care Cancer 22(7):1807-1814

59. Fallon MT, Storey DJ, Krishan A, Weir CJ, Mitchell R, FleetwoodWalker SM, Scott AC, Colvin LA (2015) Cancer treatment-related neuropathic pain: proof of concept study with menthol-a TRPM8 agonist. Support Care Cancer 23(9):2769-2777

60. Farshchian N, Alavi A, Heydarheydari S, Moradian N (2018) Comparative study of the effects of venlafaxine and duloxetine on chemotherapy-induced peripheral neuropathy. Cancer Chemother Pharmacol 82(5):787-793

61. Kautio AL, Haanpää M, Leminen A, Kalso E, Kautiainen H, Saarto $\mathrm{T}$ (2009) Amitriptyline in the prevention of chemotherapy-induced neuropathic symptoms. Anticancer Res 29(7):2601-2606

62. Reinhardt F, Wetzel T, Vetten S, Radespiel-Tröger M, Hilz MJ, Heuss D, Neundörfer B (2000) Peripheral neuropathy in chronic venous insufficiency. Muscle Nerve 23(6):883-887

63. Blanton HL, Brelsfoard J, DeTurk N, Pruitt K, Narasimhan M, Morgan DJ, Guindon J (2019) Cannabinoids: current and future options to treat chronic and chemotherapy-induced neuropathic pain. Drugs 79(9):969-995

64. Lynch ME, Cesar-Rittenberg P, Hohmann AG (2014) A doubleblind, placebo-controlled, crossover pilot trial with extension using an oral mucosal cannabinoid extract for treatment of chemotherapyinduced neuropathic pain. J Pain Symptom Manag 47(1):166-173 
65. Stubblefield MD et al (2009) NCCN task force report: management of neuropathy in cancer. J Natl Compr Cancer Netw 7(Suppl 5):S1S26 quiz S27-8

66. European Medicines Agency (EMA). https://www.ema.europa.eu/ en/medicines/human/EPAR/qutenza\#authorisation-details-section. Accessed: 20/10/22

67. Haanpää M, Cruccu G, Nurmikko TJ, McBride WT, Docu Axelarad A, Bosilkov A, Chambers C, Ernault E, Abdulahad AK (2016) Capsaicin 8\% patch versus oral pregabalin in patients with peripheral neuropathic pain. Eur J Pain 20(2):316-328

68. Anand P, Elsafa E, Privitera R, Naidoo K, Yiangou Y, Donatien P, Gabra H, Wasan H, Kenny L, Rahemtulla A, Misra P (2019) Rational treatment of chemotherapy-induced peripheral neuropathy with capsaicin $8 \%$ patch: from pain relief towards disease modification. J Pain Res 12:2039-2052

69. Mou J, Paillard F, Turnbull B, Trudeau J, Stoker M, Katz NP (2014) Qutenza (capsaicin) 8\% patch onset and duration of response and effects of multiple treatments in neuropathic pain patients. Clin J Pain 30(4):286-294

70. Mankowski C, Poole CD, Ernault E, Thomas R, Berni E, Currie CJ, Treadwell C, Calvo JI, Plastira C, Zafeiropoulou E, Odeyemi I (2017) Effectiveness of the capsaicin $8 \%$ patch in the management of peripheral neuropathic pain in European clinical practice: the ASCEND study. BMC Neurol 17(1):80

71. Vinik AI et al (2019) Repeat treatment with capsaicin 8\% patch (179mg capsaicin cutaneous patch): effects on pain, quality of life, and patient satisfaction in painful diabetic peripheral neuropathy: an open-label, randomized controlled clinical trial. J Curr Med Res Opin 2:388-401

72. Kennedy WR, Vanhove GF, Lu SP, Tobias J, Bley KR, Walk D, Wendelschafer-Crabb G, Simone DA, Selim MM (2010) A randomized, controlled, open-label study of the long-term effects of NGX-4010, a high-concentration capsaicin patch, on epidermal nerve fiber density and sensory function in healthy volunteers. $\mathrm{J}$ Pain 11(6):579-587

73. Hustedt IW, Heskamp ML, Maihöfner CG (2014) [Effectiveness and safety of local treatment of painful chemotherapy-induced polyneuropathies with capsaicin $8 \%$ cutaneous patch]. Deutscher Schmerzkongress, Hamburg, Germany, 22-25 Oct 2014, Poster abstract no. 258 accepted, poster no. P05.06

74. Hustedt IW, Heskamp ML, Maihöfner CG (2014b) Treatment of chemotherapy-induced polyneuropathies: effectiveness and safety of the capsaicin $8 \%$ cutaneous patch. WCP (IASP) Buenos Aires 611 Oct 2014, Poster abstract no. 3082 accepted, poster no. PF-434

75. Maihöfner CG, Heskamp ML (2014) Treatment of peripheral neuropathic pain by topical capsaicin: Impact of pre-existing pain in the QUEPP-study. Eur J Pain 18(5):671-679

Publisher's note Springer Nature remains neutral with regard to jurisdictional claims in published maps and institutional affiliations. 